\title{
Policy Practices to Maximise Social Benefit from Biosimilars
}

\author{
Inotai $\mathbf{A}^{1,2^{*}}$, Csanádi $\mathbf{M}^{1,3}$, Vitezic $\mathrm{D}^{4}$, Francetic ${ }^{5}$, Tesar $\mathrm{T}^{6}$, Bochenek $\mathrm{T}^{7}$, Lorenzovici ${ }^{8,9}$, Dylst $\mathbf{P}^{10}$ and Kaló $\mathbf{Z}^{1,2}$ \\ ${ }^{1}$ Syreon Research Institute, Budapest, Hungary \\ ${ }^{2}$ Department of Health Policy and Health Economics, Eötvös Loránd University (ELTE), Budapest, Hungary \\ ${ }^{3}$ Department of Pharmaceutics and Central Clinical Pharmacy, University of Pécs, Pécs, Hungary \\ ${ }^{4}$ University of Rijeka School of Medicine and University Hospital Centre Rijeka, Rijeka, Croatia \\ ${ }^{5}$ Center for Expert Medicine, Zagreb, Croatia \\ ${ }^{6}$ Department of Organisation and Management in Pharmacy, Comenius University in Bratislava, Bratislava, Slovakia \\ ${ }^{7}$ Department of Drug Management, Institute of Public Health, Jagiellonian University Medical College, Krakow, Poland \\ ${ }^{8}$ Syreon Research Romania, Tirgu Mures, Romania \\ ${ }^{9}$ Faculty of Technical and Human Sciences, Sapientia University, Tirgu Mures, Romania \\ ${ }^{10}$ Biosimilar Medicines Group, Medicines for Europe, Brussels, Belgium
}

\begin{abstract}
Biosimilar medicines can generate savings to the society. However, if patient access to original biologic medicines is limited, the main benefit of biosimilar medicines is to treat more patients from the same health care budget and hence generate more health gain.

The aim of this policy paper is to provide recommendations on how to maximise the value proposition of biosimilar medicines in lower income countries with more limited health care resources.

From the clinical perspective, first line use of multi-source, off-patent biologics should be considered for all treatment naïve patients before prescribing any other patented biologic therapies without major added benefit. Systematic literature reviews indicate that significant and quantifiable economic benefits from switching patients on maintenance biologic to biosimilars should not be sacrificed for non-quantifiable and fairly low risks of immunogenicity, hence a single switch of patients from an original biologic to its biosimilar alternative under medical supervision should be mandated after patent expiry.

From the health economic perspective authors advocate the use of cost-utility analysis to evaluate the full economic value of biosimilars. In sensitivity analyses decision-makers can explore the level of risk associated with immunogenicity, where switch of patients treated by original biologics is not the preferred policy approach anymore. However, authors still advocate the collection of real world pharmacovigilance data after switching patients to biosimilars, and reassessment of cost-effectiveness ratio after more real-world data becomes available.
\end{abstract}

Appropriateness of biosimilar drug policies is equally important to market access of new biologic therapies in lower income countries.

Keywords: Pharmaceutical policy; Biologic; Biosimilar; Social benefit; Prescription guidelines

Abbreviations: BIA: Budget Impact Analysis; CEA: Cost-effectiveness Analysis; CMA: Cost-minimization Analysis; CUA: Cost-utility Analysis; INN: International Non-proprietary Name; PVA: Price Volume Agreement; QALY: Quality Adjusted Life Years; SmPC: Summary of Product Characteristics

\section{Introduction}

\section{Objective of off-patent pharmaceutical policies}

The main policy objective of health care decision-makers is to maximize health gain for the population [1] by improving the allocative efficiency of limited resources. The objective of off-patent drug policies is usually defined as reduction in health expenditures without compromising health outcomes [2]. If clinical studies indicate equal outcomes between an off-patent medicine and the originator, then the more cost-effective medicines can be selected by Cost-minimization Analysis (CMA) [3].

Biosimilar medicines can generate savings to the society [4-6]. They are expected to reduce drug costs, although to a lesser degree than seen with small-molecule generic drugs [7]. However, health care policymakers should take measures to increase the use of biosimilar medicines [8], partly by managing concerns related to efficacy and safety of biosimilar medicines raised by different stakeholders, including clinicians, patients, payers and manufacturers of originator biological medicines [9].

Interestingly the objective of biosimilar policies can be defined differently in countries with significant resource constraints, where accessibility of patients to high-cost biologic medicines is limited [10]. In these countries, biosimilar medicines also compete with nonbiologic therapies in case of those patients, who cannot have access to original biologic medicines. As health outcomes on non-biologic and biosimilar medicines are different, the traditionally applied CMA is not an appropriate methodology to understand the true economic value of biosimilar medicines.

*Corresponding author: Inotai $\mathrm{A}, \mathrm{PharmD}, \mathrm{PhD}$, Syreon Research Institute, Hungary-1142, Budapest, Mexikói Str. 65/A, Hungary, Tel: +36-1-787-0083; Fax: +361-220-5768; E-mail: andras.inotai@syreon.eu

Received June 20, 2017; Accepted July 07, 2017; Published July 17, 2017

Citation: Inotai A, Csanádi M, Vitezic D, Francetic I, Tesar T, et al. (2017) Policy Practices to Maximise Social Benefit from Biosimilars. J Bioequiv Availab 9: 467472. doi: 10.4172/jbb.1000346

Copyright: (c) 2017 Inotai A, et al. This is an open-access article distributed under the terms of the Creative Commons Attribution License, which permits unrestricted use, distribution, and reproduction in any medium, provided the original author and source are credited. 
The aim of this policy paper is to provide recommendations on how to maximise the value proposition of biosimilar medicines in lower income European countries with more limited health care resources.

\section{Access Restrictions in Lower Income Countries with Limited Resources}

Launch price of innovative pharmaceuticals, including high-cost biologic medicines is determined according to highest acceptable price by payers in large size and high-income countries with the greatest market potential [11]. There are two reasons why these prices are usually not justifiable in lower income countries. At first, savings from avoided medical events due to improved drug therapies are less in countries with lower price level of medical services and lower salaries of health care professionals. Secondly, less affluent countries cannot afford to pay as much for one unit of health gain as higher income countries.

Unfortunately, the European external price referencing system and the encouragement of parallel trade by several higher income European countries such as Germany, The Netherlands and the United Kingdom $[12,13]$ prevent manufacturers of originator biologic medicines from reducing the list price of their high-cost products in lower income European countries, including Eastern Europe [14]. At Western European prices, new high-cost biologic medicines are usually not costeffective in lower income Eastern European countries.

On the other hand, there is a strong pressure on health care decision makers from politicians, patient advocates, clinicians and the pharmaceutical industry to reimburse new biologic medicines, especially in key priority disease areas [15]. To respond to this political pressure several biologic medicines not meeting local cost-effective thresholds are reimbursed in lower income European countries, however various access restrictions are implemented to ensure the sustainability of health care financing [16]. These restrictions can influence prescribers, patients and manufacturers.

Some of the access restrictions have major influence on health care providers either at individual prescriber or institutional level. In many countries, the prescribing practice of physicians is guided by financial protocols or specific guidelines which may restrict the prescription of biologic medicines for only a subgroup of patients compared to the licensed indication described by the Summary of Product Characteristics (SmPC). Guidelines may also allow high-priced biologics to be prescribed only as second line treatments, after a first line and lower priced non-biologic alternative failed. In other cases, treatment duration of biologic medicines can be restricted in financing protocols compared to the treatment duration specified in the SmPC, and so the medicine could be reimbursed only up to first couple of cycles. Payers may introduce volume restrictions to individual specialists or institutions either by capping the number of treated patients or prescribed units of biologic medicines. If payers narrow the list of centers who can prescribe high cost biologic medicines with reimbursement, some physicians outside those centers may seek for cheaper alternative therapies, as they do not want to lose their patients.

Payers may apply various restriction techniques by influencing patients. Waiting lists to prevent immediate access to high-cost medicines are introduced even in severe diseases with rapid progression, such as oncology. If the disease progresses while the patient is on the waiting list, the therapy may not be necessary anymore. In some cases, the biologic therapy may be covered from a special budget with fairly slow, "bureaucratic" approval process for each prescription of individual patients. Significant co-payment associated with high priced biologic medicines may not only increase the cost consciousness of patients, but can also limit or even block the access of patients from lower socioeconomic classes to these medicines. Even if the medicine is fully reimbursed, no reimbursement or limited access to the concomitant molecular diagnostics or other related services may represent significant financial burden for poorer patients. If prescription of medicines is restricted to selected centers in large cities, travel time and costs for patients from rural areas may represent significant access barrier.

Finally, payers may restrict the utilisation of high-cost biologic medicines by influencing manufacturers. Payers may delay the reimbursement decision with objective reasons, e.g. the reimbursement dossier cannot be submitted by manufacturers until at least 5 other European countries put the medicine to the reimbursement list. However, in many other cases the reason for delaying the reimbursement is not so objective. Price Volume Agreements (PVA) with unreasonably low volume of medicines may represent an efficient incentive to manufacturers to avoid significant payback by keeping the utilisation at low level.

As a consequence of these restrictions, even if biologic medicines are reimbursed in several lower income countries, the real-world utilisation of these medicines is fairly low, as significant proportion of patients cannot get access to high-cost therapies.

\section{Value Propositions of Off-patent Biologics in Countries with Limited Resources}

There are three main scenarios to determine the value proposition of biosimilar medicines according to the status of patient access to original biologic medicines (Table 1).

If the original biologic product is reimbursed without any volume and access restrictions, the main objective of using biosimilar medicines is to generate savings in health expenditures without compromising health outcomes. This disinvestment scenario is mainly applicable for higher income countries. If the original biologic product is reimbursed with volume and access restrictions, the main objective of biosimilar medicines is to treat more patients from the same health care budget, and hence generate more health gain (Figure 1). This special investment scenario is applicable for lower income EU member states and other middle-income countries. If the original biologic product is not reimbursed at all, more affordable biosimilar medicines may create an opportunity for public reimbursement, however, incremental budget is needed to generate more health gain. This investment scenario is applicable for low income countries [2].

In conclusion, in countries with restricted or no access to original biologic medicines the main benefit of biosimilar medicines is not related to their cost-saving potential, the objective of biosimilar policies has to be defined from an investment perspective [17-19]. The key question is which policy tools can facilitate the increased utilisation of biosimilar medicines to maximise the health gain from a given health care budget. These tools can be assessed from clinical and health economic perspectives.

\section{Considerations for Clinical Practice}

More extended utilisation of biosimilar medicines necessitates the reconsideration of current therapeutic guidelines dealing with biologic products. In the majority of countries generic products are first line treatment options in high-prevalent diseases such as hypertension, type 2 diabetes or major depression [20-23]. Similarly, to these cases, first line use of biosimilar medicines should be considered for all treatment naïve 
Citation: Inotai A, Csanádi M, Vitezic D, Francetic I, Tesar T, et al. (2017) Policy Practices to Maximise Social Benefit from Biosimilars. J Bioequiv Availab 9: 467-472. doi: 10.4172/jbb.1000346

\begin{tabular}{|c|c|c|c|}
\hline & $\begin{array}{c}\text { Originator is reimbursed without access limits } \\
\text { to patients }\end{array}$ & $\begin{array}{c}\text { Originator is reimbursed with access limits } \\
\text { to patients }\end{array}$ \\
\hline Value proposition & Savings in drug budget & $\begin{array}{l}\text { No increase in drug budget } \\
\text { Improved patient access } \\
\text { Decision }\end{array}$ & Health gain \\
\hline Disinvestment & Re-investment of savings \\
\hline
\end{tabular}

Table 1: Value proposition of biosimilars in different access-restriction settings.

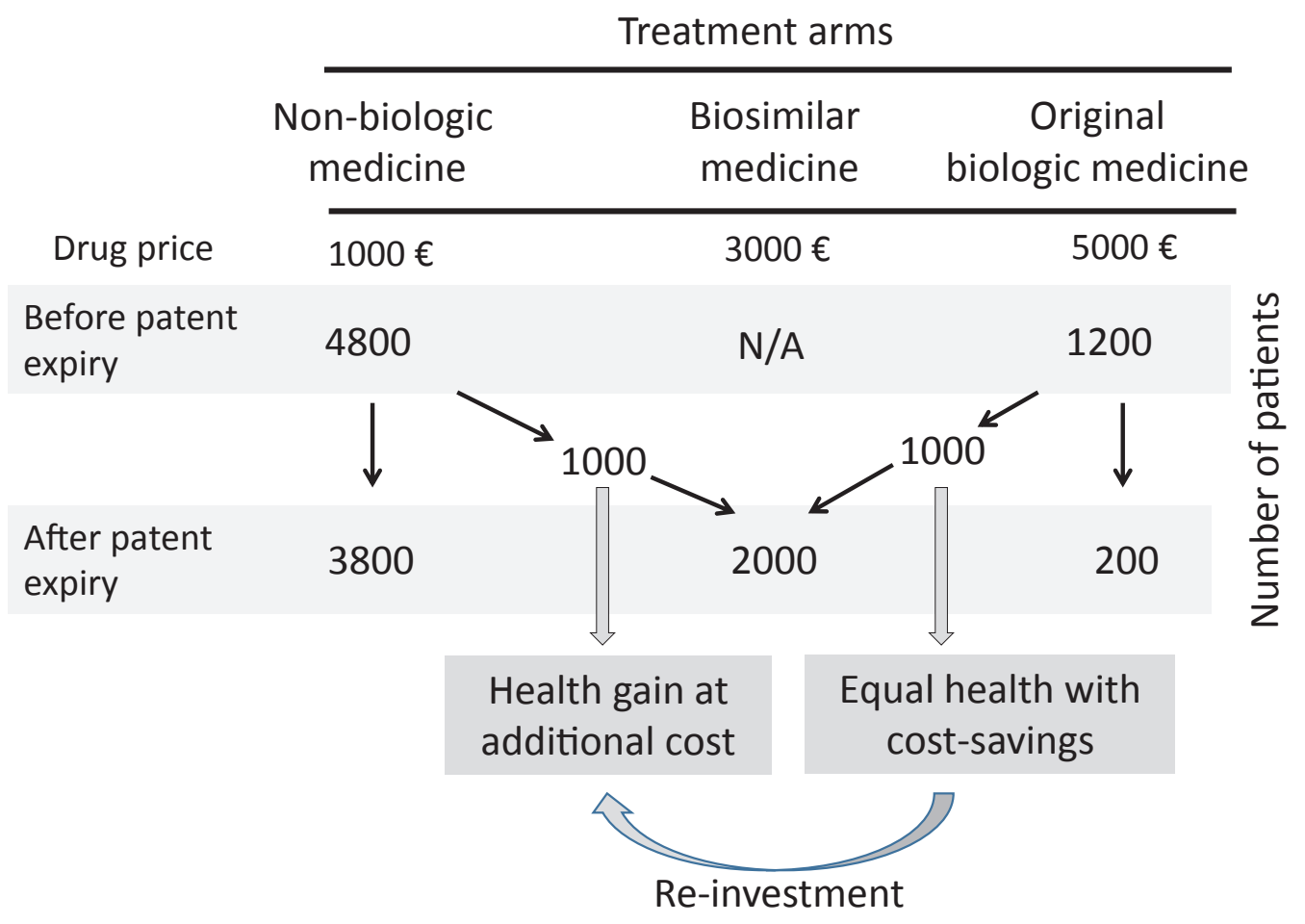

Improved population health with neutral budget impact

Figure 1: Example of improving patient access with neutral budget impact by increasing utilisation of biosimilar medicines.

patients before prescribing any other patented biologic therapy, if major added benefit of those biologic medicines compared to biosimilar medicines is not proven.

Even in some higher income countries clinical guidelines have changed to this direction recently, as price erosion of multi-source biologic medicines has become massive [24]. In Norway key opinion leaders envisaged first-line use of biosimilar medicines for biologic naive patients in inflammatory bowel disease [25]. In Denmark, similar approach has been facilitated by the national council for expensive hospital medicines in rheumatology and gastroenterology $[26,27]$. Clinical guidelines and financial protocols should be adjusted accordingly in lower income countries as well. According to recent survey in New Zealand most physicians indicated that they would prescribe biosimilars for all clinical conditions in which biosimilars are cost-effective alternatives to biologic medicines. However, it is important to provide communication guidance to clinicians on how to explain biosimilars effectively to patients in order to reduce potential objections [28].
As many biologic medicines are used in chronic diseases, the increased utilisation of biosimilar medicines in patients who are currently treated with patented biologic medicines should also be considered. Nevertheless, switching clinically stable patients from an original biologic medicine to its biosimilar alternative has never been a straightforward decision for clinicians [8]. Additionally, debate on immunogenicity has been fuelled by manufacturers of original biologic medicines [29]. Recently, however, several systematic reviews evaluated the clinical consequences of switching to biosimilar medicines, but none of them concluded increased risk of adverse events or efficacy loss [30-33]. These reviews, along with evidence generated from recent clinical trials indicate that significant and quantifiable economic benefits from switching patients on maintenance biologic medicines to their biosimilar alternatives under medical supervision should not be sacrificed for non-quantifiable and fairly low risks of immunogenicity. This does not necessarily mean that multiple switching between biosimilar medicines is justifiable; however, a single switch of high cost original to a more affordable biosimilar medicine can be applied in clinical practice, especially in lower income countries with limited resources. 
Citation: Inotai A, Csanádi M, Vitezic D, Francetic I, Tesar T, et al. (2017) Policy Practices to Maximise Social Benefit from Biosimilars. J Bioequiv Availab 9: 467-472. doi: 10.4172/jbb.1000346

\section{Health Economic Considerations}

An increasing number of countries demand evidence about the cost-effectiveness of biosimilars to inform pharmaceutical reimbursement decisions. CMA is the standard approach to prove the cost-effectiveness of small molecule generic medicines, as the same health gain is produced at lower costs. According to Simoens et al., costeffectiveness analysis of biosimilars is more complicated, as necessary evidence to obtain market authorization may not be sufficient to inform reimbursement decisions [3]. Consequently, CMA may not be the optimal approach for the economic evaluation of biosimilars in several different decision contexts.

The variety of such decision problems can be categorized based on: 1) Previous therapy of target patient groups and 2) Selection of the policy relevant comparator as described in Table 2.

Scenario $1 \mathrm{~A}$ is relevant only in those lower income countries, where access to biologic medicines is restricted. For those patients who cannot access to original biologic medicines otherwise, affordable biosimilar medicines may offer extra health gain at an incremental cost. As health gain of the compared therapies is not equal, Cost-effectiveness Analysis (CEA) or its alternative, Cost-utility Analysis (CUA) has to be applied, in which the health gain is aggregated in Quality Adjusted Life Years (QALYs).

Scenario $2 \mathrm{~A}$ is a relevant policy scenario in every country. Based on the best available evidence biosimilars offer equal health gain to original biologic medicines [34] and CMA indicates which medicine is the more cost-effective treatment option.

Scenario $3 \mathrm{~A}$ can be a policy relevant option in all countries, where decision-makers try to maximise societal benefits from biosimilar medicines. If there is no clear preference among different originator biologic medicines in the treatment guidelines, and relative effectiveness analyses indicate no or minimal difference between patented biologic alternatives, biosimilar medicines provide fairly similar health gain at lower costs, and therefore they should be selected before any other original biologic medicine.

Scenario 1B may not be the first option to maximise societal benefits from biosimilar medicines. However, in those countries, where due to economic reasons patients could start their treatment with less effective non-biologic therapies, switch to biosimilar medicines may provide them extra health gain at incremental costs. On the other hand, until disease is controlled by more affordable small molecule medicines, switch may not be clinically relevant in several disease areas.

Scenario $2 \mathrm{~B}$ is a highly debated option due to the potential risk of immunogenicity, but still it has already been implemented in Denmark or Norway. Overall, the opportunity cost of not switching patients to biosimilar medicines is greater in lower income than higher income countries, as health care budgets are more limited. Current evidence suggests that a single switch of patients treated with original biologic to biosimilar products after patent expiry is not associated with increased risk of adverse reactions or loss of efficacy [30-33]. When there is clinical trial or registry based evidence about continued efficacy and nonincreased adverse event rate after switching of a biological medicine to its biosimilar alternative, expedited review with CMA is sufficient to select the most cost-effective treatment strategy. However, when such direct evidence is not available authors advocate the use of CEA or CUA to evaluate the full economic value of biosimilar medicines. In the sensitivity analyses of such economic evaluations decisionmakers can explore how much should be the risk of immunogenicity, where switch is not the preferred policy approach anymore. If that risk is unrealistically high, societies lose from not switching patients to a more affordable alternative. However, the collection of real world pharmacovigilance data after switching the patients to biosimilar medicines is still recommended and reassessment of cost-effectiveness is needed after more real-world data become available [34].

Scenario 3B may be unrealistic from the clinical point of view, as advanced therapy of patients with chronic diseases should not be changed until disease progression.

\section{Policy Implications}

Payers have to take a strategic approach to increase societal benefit from biosimilar medicines [35]. Relying on free-market incentives may not be strong enough mainly due to hypothetical concerns related to the evidence base of biosimilar medicines and promotional campaigns organized by manufacturers of original biologic medicines. Hence, active government interventions instead of 'passive disinvestment' policies are needed to correct for market failures [36].

\begin{tabular}{|c|c|c|c|c|}
\hline & & \multicolumn{3}{|c|}{ Comparator } \\
\hline & & Non-biologics (1) & Biologics with same INN (2) & Other biologics with different INN (3) \\
\hline \multirow{3}{*}{$\begin{array}{l}\text { New patients } \\
\text { (A) }\end{array}$} & decision problem & \multicolumn{3}{|c|}{ Choice of starting therapy } \\
\hline & necessary clinical evidence & $\begin{array}{l}\text { Relative effectiveness of biosimilar } \\
\text { compared to non-biologics }\end{array}$ & Phase III trial result & $\begin{array}{l}\text { Relative effectiveness of biosimilar } \\
\text { compared to biologics with different } \\
\text { INN }\end{array}$ \\
\hline & $\begin{array}{l}\text { necessary health economic } \\
\text { analysis* }\end{array}$ & $\begin{array}{ll}\text { - } & \text { CUA } \\
\text { - } & \text { BIA } \\
\end{array}$ & $\begin{array}{l}\text { - } \text { CMA } \\
\text { - } \text { BIA }\end{array}$ & $\begin{array}{l}\text { - } \\
\text { - } \\
\text { BIA }\end{array}$ \\
\hline \multirow{3}{*}{$\begin{array}{l}\text { Stable } \\
\text { patients on } \\
\text { therapy }(B)\end{array}$} & decision problem & $\begin{array}{l}\text { single switch of patients on non- } \\
\text { biologicals to biosimilar }\end{array}$ & $\begin{array}{l}\text { single switch of patients on original biologic } \\
\text { to its biosimilar alternative }\end{array}$ & \multirow{3}{*}{ not realistic clinical scenario } \\
\hline & necessary clinical evidence & $\begin{array}{l}\text { Relative effectiveness of switching to } \\
\text { biosimilar compared to staying on non- } \\
\text { biologics }\end{array}$ & $\begin{array}{ll}\text { - } & \text { Phase III trial results (if available) } \\
\text { - } & \text { Risk assessment for immunogenicity } \\
\text { based on literature review or existing } \\
\text { clinical trial data } \\
\text { - } & \text { (Ongoing data collection) }\end{array}$ & \\
\hline & $\begin{array}{l}\text { necessary health economic } \\
\text { analysis* }\end{array}$ & $\begin{array}{ll}\text { - } & \text { CEA/CUA } \\
\text { - } & \text { Budget impact }\end{array}$ & $\begin{array}{ll}\text { - } & \text { CMA (in expedited review) or CEA/CUA } \\
\text { (in full review) } \\
\text { - } & \text { Budget impact }\end{array}$ & \\
\hline
\end{tabular}

"CMA: Cost-minimization Analysis; CEA: Cost-effectiveness Analysis; CUA: Cost-utility Analysis; BIA: Budget Impact Analysis; INN: International Non-proprietary Name

${ }^{*}$ Choice of economic evaluation depends on the assumption and/or evidence on equal health gain

Table 2: Relevance of clinical evidence and health economic methods in different scenarios. 
Citation: Inotai A, Csanádi M, Vitezic D, Francetic I, Tesar T, et al. (2017) Policy Practices to Maximise Social Benefit from Biosimilars. J Bioequiv Availab 9: 467-472. doi: 10.4172/jbb.1000346

In lower income countries, the following policy actions are recommended to maximise social benefits from follow-on biologic medicines:

Recommendations for public administration of biosimilar medicines: (a) Introduction of administrative tools and policy measures to incentivize the choice for more affordable biosimilars. (b) Expedited price and reimbursement process to facilitate the timely market entry of biosimilars.

Recommendations for clinical guidelines: (a) Multisource biologic medicines should be first line biologic therapy for all patients. More expensive patented biologic medicines with no proven significant clinical benefit compared to biosimilar medicines should be only second line options. (b) Single switch of patients from an original biologic medicine to its more affordable biosimilar alternative under medical supervision should be mandated after patent expiry. (c) Physicians should not only be informed about scientific evidence on biosimilars but also guided on how to educate appropriately their patients on these medicines.

Recommendations for evidence base of policy decisions: (a) CEA or CUA should be applied to judge the full economic value of biosimilar medicines except in those cases, when biosimilar medicines are compared to their original biologic alternative for treatment naïve patients. (b) Budget impact analysis should be used to estimate the savings from biosimilar medicines, if there is no patient access limit to biologic medicines, or the incremental budget, if patient access to biologic medicines is restricted.

Recommendations for managing uncertainty: Public policymakers may consider different approaches to manage uncertainty, especially related to the switch of original biologics to its more affordable biosimilar version. (a) Ex-ante risk management: calculation of threshold for the risk of immunogenicity, where not switching patients to biosimilar medicines is the preferred option from the payers' perspective. (b) Ex-post risk management: mandate of collecting pharmacovigilance data, and risk-management plan, in case of increased risk of immunogenicity. The risk management plan may even include risk-sharing agreements with manufacturers of biosimilar medicines.

\section{Conclusion}

Sustainability of health care financing is challenging in all countries, and this is especially true for lower income economies. In these countries, the main policy focus is on patient access to new and expensive health technologies which requires appropriate biosimilar drug policies. However, the key success criterion of public health programs is how to improve the utilisation and persistence with more affordable medical technologies.

\section{Acknowledgement}

Syreon Research Institute received financial support from Medicines for Europe to prepare this paper. The authors summarized their independent professional opinions and take full responsibility for potential errors in the manuscript.

\section{References}

1. Kutzin J (2008) Health financing policy: a guide for decision-makers. Health financing policy paper. Copenhagen, WHO Regional Office for Europe.

2. Kaló Z, Holtorf AP, Alfonso-Cristancho R, Shen J, Ágh T, et al. (2015) Need for multicriteria evaluation of generic drug policies. Value Health 18: 346-351.

3. Simoens S, Verbeken G, Huys I (2012) Biosimilars and market access: a question of comparability and costs? Target Oncol 7: 227-231.
4. Cornes $P$ (2012) The economic pressures for biosimilar drug use in cancer medicine. Targeted Oncol 7: S57-S67.

5. Muller R, Renner C, Gabay C, Cassata G, Lohri A, et al. (2014) The advent of biosimilars: challenges and risks. Swiss Med Wkly 144: w13980.

6. Emmanouilides CE, Karampola MI, Beredima M (2016) Biosimilars: Hope and concern. J Oncol Pharm Pract 22: 618-624.

7. Singh SC, Bagnato KM (2015) The Economic Implications of Biosimilars. Am J Manag Care 21: S331-S340.

8. Dylst P, Vulto A, Simoens S (2014) Barriers to the Uptake of Biosimilars and Possible Solutions: A Belgian Case Study. Pharmacoeconomics 32: 681-91.

9. Moorkens E, Jonker-Exler C, Huys I, Declerck P, Simoens S, et al. (2016) Overcoming barriers to the market access of biosimilars in the european union: the case of biosimilar monoclonal antibodies. Front Pharmacol 7: 193.

10. Brodszky V, Rencz F, Péntek M, Baji P, Lakatos PL, et al. (2016) A budget impact model for biosimilar infliximab in Crohn's disease in Bulgaria, the Czech Republic, Hungary, Poland, Romania, and Slovakia. Expert Rev Pharmacoecon Outcomes Res 16: 119-125.

11. Kaló Z, Annemans L, Garrison LP (2013) Differential pricing of new pharmaceuticals in lower income European countries. Expert Rev Pharmacoecon Outcomes Res 13: 735-741.

12. Duso T, Herr A, Suppliet M (2014) The welfare impact of parallel imports: a structural approach applied to the German market for oral anti-diabetics. Health Econ 23: 1036-1057.

13. Costa-Font J, Kanavos $P$ (2007) Constrained competition in parallel drug importation: the case of simvastatin in Germany, the Netherlands, and the United Kingdom. Gac Sanit 21: 53-59.

14. Elek P, Takács E, Merész G, Kaló Z (2017) Implication of external price referencing and parallel trade on pharmaceutical expenditure: indirect evidence from lower-income European countries. Health Policy Plan 32: 349-358.

15. Inotai A, Petrova G, Vitezic D, Kaló Z (2014) Benefits of investment into modern medicines in Central-Eastern European countries. Expert Rev Pharmacoecon Outcomes Res 14: 71-79.

16. Inotai A, Csanadi M, Petrova G, Bochenek T, Tesar T, et al. (2016) Mapping of the Biosimilar Drug Policy in 10 Central Eastern European Countries. Value in Health 19: A504-A505.

17. Aapro M, Cornes P, Sun D, Abraham I (2012) Comparative cost efficiency across the European $\mathrm{G} 5$ countries of originators and a biosimilar erythropoiesisstimulating agent to manage chemotherapy-induced anemia in patients with cancer. Ther Adv Med Oncol 4: 95-105.

18. Aapro M, Cornes P, Abraham I (2012) Comparative cost-efficiency across the European G5 countries of various regimens of filgrastim, biosimilar filgrastim, and pegfilgrastim to reduce the incidence of chemotherapy-induced febrile neutropenia. J Oncol Pharm Pract 18: 171-179.

19. Elek P, Harsányi A, Zelei T, Csetneki K, Kaló (2017) Policy objective of generic medicines from the investment perspective: The case of clopidogrel. Health Policy 121: 558-565.

20. WHO (2011) Global burden of disease.

21. James PA, Oparil S, Carter BL, Cushman WC, Dennison-Himmelfarb C, et al (2014) Evidence-based guideline for the management of high blood pressure in adults: report from the panel members appointed to the Eighth Joint National Committee (JNC 8). JAMA 311: 507-520.

22. International Diabetes Federation (2012) Global guideline for type 2 diabetes.

23. Davidson JR (2010) Major depressive disorder treatment guidelines in America and Europe. J Clin Psychiatry 71: e04.

24. Stanton D (2015) Biosimilar discounts and switching will wipe-out J\&J's Remicade in Norway.

25. http://www.pharmatimes.com/news/celltrion_remicade_biosimilar_gathers momentum_in_eu_971086

26. Lunddahl B (2016) Pharmacovigilance on biologicals and biosimilars: a Danish perspective. GaBI J 5: 123-124.

27. Glintborg B, Sørensen IJ, Loft AG, Lindegaard H, Linauskas A (2017) A nationwide non-medical switch from originator infliximab to biosimilar CT-P13 in 802 patients with inflammatory arthritis: 1-year clinical outcomes from the DANBIO registry. Annals of the Rheumatic Diseases, annrheumdis-2016. 
Citation: Inotai A, Csanádi M, Vitezic D, Francetic I, Tesar T, et al. (2017) Policy Practices to Maximise Social Benefit from Biosimilars. J Bioequiv Availab 9: 467-472. doi: 10.4172/jbb.1000346

28. Hemmington A, Dalbeth N Jarrett N, Fraser AG, Broom R, et al. (2017) Medical specialists' attitudes to prescribing biosimilars. Pharmacoepidemiol Drug Saf 26: $570-577$

29. Editorial (2013) Building a wall against biosimilars. Nat Biotechnol 31: 264.

30. Papamichael K, Van Stappen T, Jairath V, Gecse K, Khanna R, et al. (2015) Pharmacological aspects of anti-TNF biosimilars in inflammatory bowel diseases. Aliment Pharmacol Therapeut 42: 1158-1169.

31. Ebbers HC, Muenzberg M, Schellekens H (2012) The safety of switching between therapeutic proteins. Expert Opin Biol Ther 12: 1473-1485.

32. McKeage K (2014) A review of CT-P13: an infliximab biosimilar. BioDrugs 28: 313.
33. Inotai A, Prins CPJ, Csanádi M, Vitezic D, Codreanu C et al. (2017) Is there a reason for concern or is it just hype?-A systematic literature review of the clinical consequences of switching from originator biologics to biosimilars. Expert Opin Biol Ther pp: 1-12.

34. Stewart A, Aubrey P, Belsey J (2010) Addressing the health technology assessment of biosimilar pharmaceuticals. Curr Med Res Opin 26: 2119-2126.

35. Mestre-Ferrandiz J, Towse A, Berdud M (2016) Biosimilars: How can payers get long-term savings? Pharmacoeconomics 34: 609- 616.

36. Parkinson B, Sermet C, Clement F, Crausaz S, Godman B, et al. (2015) Disinvestment and value-based purchasing strategies for pharmaceuticals: an international review. Pharmacoeconomics 33: 905-924. 